\title{
Rasch Analysis of the Central Life Interest Measure
}

\author{
Neal Schmitt \\ Michigan State University
}

Rasch item analyses were conducted and estimates of item residuals correlated with various demographic or person variables to investigate item bias in an attitude scale. Analysis revealed that the model fit the data well and that none of the demographic variables accounted for greater than $7 \%$ of the residual variance. Similar analyses of other attitude scales as well as aptitude tests should be useful.

The use of latent trait theory to solve various problems in aptitude measurement has been described frequently (Hambleton \& Cook, 1977; Lord, 1977; Wright, 1977). These authors suggest that attitude measurement would also benefit by use of these models; however, too few such applications exist in the literature. Perline, Wright, and Wainer (1979) showed that Rasch's (1966) psychometric model is really an example of additive conjoint measurement applied to empirical data. Similarly, Wainer, Fairbank, and Hough (1978) provided data that indicated that a Rasch-type latent trait analysis yielded scale values similar to those obtained by a paired comparison technique. The Wainer et al. (1978) paper also included a comparison of scale values obtained in different ethnic groups. Much earlier, Thurstone and Chave (1929) and Rasch

APPLIED PSYCHOLOGICAL MEASUREMENT

Vol. 5, No. 1, Winter 1981, pp. 3-10

(C) Copyright 1981 Applied Psychological Measurement Inc.
(1960) had proposed similar procedures for the measurement of attitude. The present paper represents an attempt to apply latent trait analysis to the Central Life Interest measure developed and researched by Dubin and his colleagues (Dubin, 1956; Dubin \& Champoux, 1974; Dubin \& Goldman, 1972).

The Central Life Interest (CLI) measure assesses the degree to which an individual chooses the work world as his/her preferred place to enact various behaviors. People who view work as central to their lives and whose job is reasonably positive should be satisfied with their jobs. People who are job oriented, however, would not be expected to be as sensitive to positive or negative features of their jobs.

The CLI questionnaire measures a person's central life interest by describing a behavior and asking for the setting in which the respondent would most like to enact the behavior. In all items one alternative specifies the work setting, another alternative a non-job setting, and a third alternative specified no locale preference. The questionnaire contains 32 items covering behaviors dealing with membership in formal organizations, technological aspects of the environment, informal personal relations, and general, everyday activities.

An example of one of the CLI items is given below: 
I would much rather be a leader

1. in any organization, just so it's a good one.

2 . in my club or church.

3 . in my work.

For this item, the third alternative is scored as the job-oriented alternative. ${ }^{1}$

In earlier work on the CLI, a person has been classified as job oriented if he/she chose at least one-half or 16 job-oriented responses; or a respondent was scored job oriented if a total of 22 job-oriented and no preference alternatives were chosen, with a minimum of 13 being job oriented. Similar criteria were used to classify other respondents as non-job oriented or as "flexible focus" persons. In the present study this scoring procedure was altered for illustrative purposes so that the CLI score became a continuous variable rather than a categorical one. Specifically, the number of job-oriented responses was taken as the person's CLI score. Substantively, this scoring procedure also seems defensible, since it seems more realistic to measure people on a continuum ranging from extremely non-job oriented to extremely job oriented than it does to classify them into distinct groups.

The CLI construct correlates with job satisfaction, especially satisfaction with the intrinsic aspects of work (Dubin \& Champoux, 1977) and with performance evaluations on qualities such as initiative and application and cooperation (Dubin \& Champoux, 1974). However, these relationships for women tend to be marginal in their statistical significance.

The CLI was chosen as the vehicle for this illustration of latent trait analysis, specifically the Rasch (1966) model analysis, for several reasons. First, application of these models is easier and the methodology better developed for dichotomously scored items than it is for continuous Likert-type items. Second, a good many of the items contrast home and work situations and, as such, may be sex biased. The use of the Rasch

\footnotetext{
'The entire instrument used can be obtained from the
} author. model to investigate item bias in ability testing has been proposed (Wright, Mead, \& Draba, 1976) and should be informative with respect to the CLI items.

There have been numerous previous attempts to define test and item bias. Some of these attempts have defined test fairness, or lack thereof, in terms of an external criterion. A review and a comparison of some of these models has been provided by Peterson and Novick (1976) and Hunter and Schmidt (1976). These models depend on the assumption that the criterion is fair, thus employing it as a standard.

Techniques used to evaluate test bias that do not rely on an external criterion attempt to determine whether items define the same trait for different groups of people. Major attempts of this type include analysis of Item $\times$ Group interactions (Cleary \& Hilton, 1968; Jensen, 1974), analysis of Item Difficulties $\times$ Group (Jensen, 1974), and the comparison of Factor Structures $\times$ Group (Green \& Draper, 1972). Recently, Ironson and Subkoviak (1979) and Rudner, Getson, and Knight (1980) have provided a comparison of some of these techniques. A major problem with these approaches lies in the necessity of the assumption that there is an equal distribution of ability across groups.

Wright, Mead, and Draba (1976) have pointed out that the Rasch logistic response model does solve this problem. Unlike traditional procedures, the use of a logistic transformation of item difficulties yields item difficulty estimates whose information value is maximum in the center of the scale and minimum at the extremes. Floor and ceiling effects, which are problems with traditional test theory, are overcome by the logistic transformation, which expands the scale of measurement at the extremes and increases the standard error of measurement, reflecting the real situation in that less precise measurement is possible in the extremes. These Rasch estimates, if the model fits, are independent of the sample on which they are calculated. Differences between the observed data and the model described by the Rasch parameters yields in- 
formation about the sources of nonvalid or biased measurement.

In the present study a Rasch analysis (see Wright, 1977; Wright \& Douglas, 1977; Wright \& Stone, 1980) of responses to the CLI was carried out. As suggested by Wright, Mead, and Draba (1976), the residuals for all items for all persons were regressed on 10 background variables in an effort to assess bias and to provide a possible explanation for lack of fit of certain items to the group of people tested.

\section{Method}

The sample included 1,151 students enrolled in vocational programs in a community college. All students either were working at the time of the questionnaire administration or were between jobs. All were also over 25 years in age, the average age being 32 . Slightly over $50 \%(50.6)$ were female and $6 \%$ were nonwhite.

Responses were made to a mailed questionnaire that included the CLI, various demographic questions, and several other job-related attitude measures. All respondents were paid $\$ 3.00$ to return a complete questionnaire.

The respondent sample was randomly divided into two approximately equal groups. The responses of both groups were analyzed using the corrected unconditional maximum likelihood estimation routine $\mathrm{UCON}$ in the BICAL program (Wright \& Mead, 1977). Ability and difficulty estimates from the first of these two samples were then used to compute residuals for both samples. These residuals were then correlated with 10 demographic variables. These variables were chosen because of the likelihood that they might represent sources of bias in CLI scores for the respondents. However, because of the computation of 10 correlations with each of 32 variables, it seemed appropriate to cross-validate or to check the stability of these correlations.

\section{Results and Discussion}

In Table 1 are presented the results of the Rasch analysis (Wright \& Stone, 1980) for the 32 items. Estimates of item difficulty ranged from -4.3 to 4.2 in the first sample and from -4.2 to 3.3 in the second sample. The $t$ tests of fit (see Wright \& Stone, 1980, p. 77), like the difficulty estimates, were similar for both samples. It should be noted that the fit statistics were significant in both samples for Items 31 and 32, only implying that the remainder of the poor fits were likely random fluctuations from the model. The probability that 0,1 , or 2 of these tests out of a possible 32 was significant in both samples is about .57 , which raises questions concerning the importance of even these two significant findings.

The estimates of ability for different score groups are presented in Table 2 . These data are consistent with earlier data collected by Dubin and his colleagues (Dubin, 1956; Dubin \& Champoux, 1974; Dubin \& Goldman, 1972) in that respondents did not give a large number of job-oriented responses. Over $25 \%$ of the subjects in both samples gave less than 6 of 32 job-oriented responses; only $4 \%$ gave more than 13 joboriented answers; and none gave over 23 scored responses. The ability estimates ranged from -4.4 to 4.4 in the first sample and from -4.4 to 4.2 in the second sample. Unlike classical standard error estimates, which are zero when a respondent gets none or all items correct, the latent trait analysis yields the highest standard error at the extremes, where indeed precision of estimation is least accurate. Data and estimates of ability parameters were nearly identical for the two samples.

In an effort to discover why some items did not fit the group of persons tested, residuals for each of the 23 score groups for job-oriented answers to each of the 32 items were calculated in both subsamples using parameter estimates derived from Sample 1. The residuals for each item were then correlated with a set of 10 background var- 
Rasch Analysis of the CLI

Table 1

Summary of Item Analysis

\begin{tabular}{|c|c|c|c|c|c|c|c|c|}
\hline \multirow[b]{2}{*}{ Item } & \multicolumn{2}{|c|}{$\begin{array}{c}\text { Proportion of } \\
\text { People Endorsing }\end{array}$} & \multicolumn{2}{|c|}{ Difficulty } & \multicolumn{2}{|c|}{$\begin{array}{l}\text { Standard } \\
\text { Error } \\
\end{array}$} & \multirow{2}{*}{$\begin{array}{c}t-t e s t \\
\text { of } \\
\text { Fit } \\
S 1\end{array}$} & \multirow{2}{*}{$\begin{array}{c}t \text {-test } \\
\text { of } \\
\text { Fit } \\
\text { s2 }\end{array}$} \\
\hline & $\mathrm{S} 1^{\mathrm{a}}$ & S2 & S1 & $\mathrm{S} 2$ & S1 & $\mathrm{S} 2$ & & \\
\hline 29 & .89 & .90 & -4.3 & -4.2 & .2 & .2 & -0.1 & 1.8 \\
\hline 10 & .54 & .57 & -1.9 & -2.0 & .1 & .1 & -0.9 & -1.0 \\
\hline 31 & .49 & .54 & -1.7 & -1.9 & .1 & .1 & -2.2 & 2.0 \\
\hline 28 & .47 & .46 & -1.6 & -1.4 & .1 & .1 & 1.1 & 1.3 \\
\hline 2 & .46 & .48 & -1.6 & -1.5 & .1 & .1 & 0.5 & -1.9 \\
\hline 20 & .42 & .44 & -1.4 & -1.4 & .1 & .1 & -2.6 & -0.3 \\
\hline 4 & .41 & .42 & -1.3 & -1.3 & .1 & .1 & -0.5 & -1.7 \\
\hline 30 & .32 & .31 & -0.9 & -0.7 & .1 & .1 & 4.3 & 1.9 \\
\hline 3 & .32 & .34 & -0.9 & -0.9 & .1 & .1 & 0.3 & -1.7 \\
\hline 22 & .29 & .27 & -0.7 & -0.5 & .1 & .1 & 0.1 & -0.2 \\
\hline 24 & .28 & .26 & -0.7 & -0.5 & .1 & .1 & 1.7 & -0.1 \\
\hline 1 & .28 & .33 & -0.6 & -0.8 & .1 & .1 & 1.3 & -3.0 \\
\hline 32 & .27 & .27 & -0.6 & -0.5 & .1 & .1 & -2.6 & 3.1 \\
\hline 23 & .24 & .27 & -0.4 & -0.5 & .1 & .1 & 0.9 & -0.2 \\
\hline 16 & .21 & .21 & -0.3 & -0.2 & .1 & .1 & -1.5 & -0.7 \\
\hline 8 & .21 & .22 & -0.2 & -0.2 & .1 & .1 & -0.1 & -1.1 \\
\hline 15 & .20 & .21 & -0.2 & -0.1 & .1 & .1 & -2.3 & -0.8 \\
\hline 13 & .20 & .26 & -0.1 & -0.4 & .1 & .1 & -1.4 & -0.9 \\
\hline 6 & .16 & .19 & 0.1 & 0.0 & .1 & .1 & -0.4 & -1.5 \\
\hline 25 & .14 & .14 & 0.3 & 0.4 & .1 & .1 & -0.9 & -0.1 \\
\hline 21 & .12 & .14 & 0.5 & 0.4 & .1 & .1 & -1.2 & -0.3 \\
\hline 14 & .08 & .07 & 0.9 & 1.2 & .2 & .2 & -0.8 & -0.8 \\
\hline 11 & .08 & .09 & 1.0 & 0.9 & .2 & .2 & -0.3 & -0.9 \\
\hline 12 & .06 & .07 & 1.2 & 1.3 & .2 & .2 & -0.7 & -0.9 \\
\hline 7 & .06 & .05 & 1.3 & 1.5 & .2 & .2 & -1.3 & $-1 \cdot 3$ \\
\hline 17 & .05 & .05 & 1.4 & 1.6 & .2 & .2 & -1.0 & -0.7 \\
\hline 5 & .05 & .05 & 1.4 & 1.5 & .2 & .2 & -0.5 & -1.6 \\
\hline 19 & .05 & .06 & 1.6 & 1.3 & .2 & .2 & -0.5 & -0.6 \\
\hline 26 & .04 & .04 & 1.8 & 1.8 & .2 & .2 & -0.1 & 0.9 \\
\hline 27 & .04 & .05 & 1.8 & 1.5 & .2 & .2 & -0.8 & 1.2 \\
\hline 9 & .03 & .02 & 2.0 & 2.3 & .3 & .3 & -0.7 & -1.0 \\
\hline 18 & .00 & .01 & 4.2 & 3.3 & .7 & .5 & -0.1 & -0.7 \\
\hline
\end{tabular}

as1 and S2 refer to Samples 1 and 2 respectively. 
Rasch Analysis of the CLI

Table 2

Ability Estimates for Score Groups

\begin{tabular}{|c|c|c|c|c|c|c|}
\hline \multirow{2}{*}{ Score } & \multicolumn{4}{|c|}{ Number of People } & \multicolumn{2}{|c|}{ Standard Error } \\
\hline & $\frac{\text { Receiving }}{\text { Sample } 1}$ & $\frac{\text { Score }}{\text { Sample } 2}$ & Sample $\frac{\text { Abil }}{\text { S }}$ & Sample 2 & Sample 1 & $\frac{\text { Error }}{\text { Sample } 2}$ \\
\hline 1 & 13 & 09 & -4.4 & -4.4 & 1.1 & 1.1 \\
\hline 2 & 21 & 22 & -3.5 & -3.5 & 0.8 & 0.8 \\
\hline 3 & 29 & 29 & -2.9 & -2.9 & 0.7 & 0.7 \\
\hline 4 & 45 & 43 & -2.5 & -2.5 & 0.6 & 0.6 \\
\hline 5 & 55 & 52 & -2.2 & -2.2 & 0.6 & 0.6 \\
\hline 6 & 73 & 51 & -1.9 & -1.9 & 0.5 & 0.5 \\
\hline 7 & 65 & 49 & -1.7 & -1.7 & 0.5 & 0.5 \\
\hline 8 & 63 & 77 & -1.5 & -1.4 & 0.5 & 0.5 \\
\hline 9 & 58 & 59 & -1.3 & -1.2 & 0.5 & 0.5 \\
\hline 10 & 35 & 47 & -1.1 & -1.9 & 0.4 & 0.4 \\
\hline 11 & 27 & 31 & -0.9 & -0.9 & 0.4 & 0.4 \\
\hline 12 & 33 & 29 & -0.7 & -0.7 & 0.4 & 0.4 \\
\hline 13 & 25 & 21 & -0.5 & -0.5 & 0.4 & 0.4 \\
\hline 14 & 14 & 13 & -0.4 & -0.3 & 0.4 & 0.4 \\
\hline 15 & 06 & 05 & -0.2 & -0.2 & 0.4 & 0.4 \\
\hline 16 & 04 & 03 & -0.0 & 0.0 & 0.4 & 0.4 \\
\hline 17 & 05 & 03 & 0.2 & 0.2 & 0.4 & 0.4 \\
\hline 18 & 04 & 04 & 0.3 & 0.4 & 0.4 & 0.4 \\
\hline 19 & 00 & 05 & 0.5 & 0.5 & 0.4 & 0.4 \\
\hline 20 & 00 & 00 & 0.7 & 0.7 & 0.4 & 0.4 \\
\hline 21 & 00 & 02 & 0.9 & 0.9 & 0.4 & 0.4 \\
\hline 22 & 00 & 01 & 1.1 & 1.1 & 0.5 & 0.5 \\
\hline 23 & 01 & 00 & 1.3 & 1.3 & 0.5 & 0.5 \\
\hline
\end{tabular}

iables that might influence CLI responses. These 10 background variables, listed in Table 3 , were chosen because it was felt that all represented variables that might influence preference for work-related activities, even though the subject's feelings about, or involvement in, work might be different under other circumstances. Marital status, sex, and number of dependents should influence work-related choices on those items in which a family-oriented alternative is present. Age and tenure are generally significantly related to a variety of job attitudes (Locke, 1976). Father's socioeconomic status and race, in so far as they index cultural differ- ences, may be responsible for certain biases. Veteran status, based on the possibility that Vietnam veterans are alienated, may produce certain biases. Finally, the subject's native language may influence the level of understanding of all items.

Forty-one of the 320 correlations between item residuals and demographics were significant ( $p$ $<.01$ ) in Sample 1. Only 16 of these relationships were also significant $(p<.01)$ in Sample 2. Further, the sign of 9 of the original significant relationships changed in Sample 2. Multiple correlations relating each of the 32 residuals to all 10 demographic variables were also com- 
Rasch Analysis of the CLI

Table 3

Correlations Between Item Residuals and Demographics

\begin{tabular}{|c|c|c|c|c|}
\hline \multirow[b]{2}{*}{ Variable } & \multirow[b]{2}{*}{ Mean ${ }^{a}$} & \multirow[b]{2}{*}{ SD } & \multicolumn{2}{|c|}{ Significant Correlations d and Item Numbers } \\
\hline & & & Sample 1 & Sample 2 \\
\hline $\begin{array}{l}\text { Marital } \\
\text { Status }\end{array}$ & .26 & .44 & $\begin{array}{l}2(-.1), 9(.1), 12(.1), \\
17(.1), 21(.1)\end{array}$ & $\begin{array}{l}2(.0), 9(.1),(.0) \\
17(-.1), 21(.0)\end{array}$ \\
\hline Age & 32.04 & 9.11 & $\begin{array}{l}2(.1), 6(.1), 7(.1) \\
12(-.1), 16(.1), \\
20(-.2), 24(-.1) \\
26(-.1), 29(.1), \\
30(-.1), 32(.1)\end{array}$ & $\begin{array}{l}2(.0), 6(.0), 7(.1) \\
12(.0), 16(.0), 20(-.1) \\
24(-.1), 26(.1), 29(.0) \\
30(-.1), 32(.1)\end{array}$ \\
\hline Sex ${ }^{b}$ & 1.49 & .50 & $2(.2), 13(-.1)$ & $2(.1), 13(-.1)$ \\
\hline Race $^{b}$ & 1.94 & .24 & $10(-.1), 27(-.1)$ & $10(-.1), 27(-.1)$ \\
\hline Dependents & 1.78 & 1.63 & $\begin{array}{l}3(.1), 14(.1), 16(.1), \\
18(.1), 26(-.2)\end{array}$ & $\begin{array}{l}3(.0), 14(.1), 16(.1) \\
18(.1), 26(-.2)\end{array}$ \\
\hline $\begin{array}{l}\text { Veteran } \\
\text { Status } b\end{array}$ & 1.70 & .46 & $2(.2), 24(-.1)$ & $2(.1), 24(-.1)$ \\
\hline Language $b$ & 1.02 & .15 & $\begin{array}{l}3(-.1), 5(.1), 17(.1) \\
29(.1)\end{array}$ & $\begin{array}{l}3(.0), 5(.1), 17(.0) \\
29(.0)\end{array}$ \\
\hline Job Tenure ${ }^{b}$ & 3.47 & 2.97 & $\begin{array}{l}11(.1), 21(.1), 29(.1), \\
30(-.1), 32(-.1)\end{array}$ & $\begin{array}{l}11(.0), 21(.0), 29(.0) \\
30(-.1), 32(.0)\end{array}$ \\
\hline $\begin{array}{l}\text { Father's } \\
\text { SESc }\end{array}$ & 40.54 & 24.75 & $14(-.1), 23(.1), 28(-.1)$ & $14(.0), 23(-.1), 28(.0)$ \\
\hline $\begin{array}{l}\text { Respondent } \\
\text { SESC }\end{array}$ & 45.98 & 20.09 & $8(-.1), 30(-.1)$ & $8(-.1), 30(.0)$ \\
\hline
\end{tabular}

a Mean and SD are for the combined sample.

bMarital status was coded $0=$ single, $1=$ married; sex, $1=$ male, $2=$ female; race, $1=$ non-white, 2 =white; veteran status, $1=$ veteran, $2=$ nonveteran; language, $1=$ English speaking native language, $2=0$ ther native language; job tenure, coded from less than 6 months to more than 10 years - the mean corresponding to about 2.5 years.

'Socioeconomic status was coded according to the subjects' fathers' jobs and the respondents' jobs using the Duncan index (Reiss, Duncan, Hatt, \& North, 1961).

dOnly those correlations significant $(p<.01)$ in Sample 1 are reported. Correlations for the same items in Sample 2 are reported; those above approximately .08 are statistically significant.

puted. The largest multiple correlation was .3; adjusted multiple correlations ranged from negative values to a high of .2. These estimates of cross-validated $R$ (Schmitt, Coyle, \& Rauschenberger, 1977) indicate that minimal amounts of residual variance were related to the demographic variables.

\section{Conclusion}

The Rasch model fit the responses to the Central Life Interest measure remarkably well. Only 2 of the 32 items in the measure failed to fit the model in both samples. This is especially important because of the large sample sizes in both 
evaulations of the model. It is also apparent by comparing Tables 1 and 2 that estimates of ability and difficulty were nearly identical across samples.

Further, although some of the demographic variables were significantly correlated with the item residuals, variance shared by item residuals and demographic indices did not exceed $7 \%$ for any of the items. This is particularly impressive as regards the Rasch model, since a priori the demographic variables chosen were likely correlates of the central life interest construct.

\section{References}

Cleary, T. A., \& Hilton, T. L. An investigation of item bias. Educational and Psychological Measurement, 1968, 28, 61-75.

Dubin, R. Industrial workers' worlds: A study of the "central life interests" of industrial workers. Social Problems, 1956, 3, 131-142.

Dubin, R., \& Champoux, J. E. Workers' central life interests and job performance. Sociology of Work and Occupations, 1974, 1, 313-326.

Dubin, R., \& Champoux, J. E. Central life interests and job satisfaction. Organizational Behavior and Human Performance, 1977, 18, 366-377.

Dubin, R., \& Goldman, D. R. Central life interests of American middle managers and specialists. Journal of Vocational Behavior, 1972, 2, 133-141.

Green, D. R., \& Draper, J. F. Exploratory studies of bias in achievement tests. Monterey, CA: CTB/McGraw-Hill, 1972.

Hambleton, R. K., \& Cook, L. L. Latent trait models and their use in the analysis of educational test data. Journal of Educational Measurement, 1977, $14,75-96$.

Hunter, J. E., \& Schmidt, F. L. Critical analysis of the statistical and ethical emplications of various definitions of test bias. Psychological Bulletin. 1976, 83, 1053-1071.

Jensen, A. R. How biased are culture-loaded tests? Genetic Psychology Monographs, 1974, 90. 185-244.

Ironson, G. H., \& Subkoviak, M. A comparison of several methods of assessing item bias. Journal of Educational Measurement, 1979, 16, 209-226.

Locke, E. A. The nature and causes of job satisfaction. In M. D. Dunnette (Ed.), Handbook of industrial and organizational psychology. Chicago: Rand McNally, 1976.

Lord, F. M. Practical applications of item characteristic curve theory. Journal of Educational Measurement, 1977, 14, 117-138.

Perline, R., Wright, B. D., \& Wainer, H. The Rasch model as additive conjoint measurement. Applied Psycholgical Measurement, 1979, 3, 237-255.

Peterson, W. S., \& Novick, M. R. An evaluation of some models for culture-fair selection. Journal of Educational Measurement, 1976, 13, 3-30.

Rasch, G. Probabilistic models for some intelligence and attainment tests. Copenhagen: Danmarks Paedogogiske Institut, 1960.

Rasch, G. An item analysis which takes individual differences into account. British Journal of Mathematical and Statistical Psychology, 1966, 19. 49-57.

Reiss, A., Duncan, O., Hatt, P., \& North, C. Occupations and social status. New York: The Free Press of Glencoe, 1961.

Rudner, L. M., Getson, P. R., \& Knight, D. L. A Monte Carlo comparison of seven biased item detection techniques. Journal of Educational Measurement, 1980, 17, 1-10.

Schmitt, N., Coyle, B. W., \& Rauschenberger, J. A Monte Carlo evaluation of three formula estimates of cross-validated multiple correlation. Psychological Bulletin. 1977, 84, 751-758.

Thurstone, L. L., \& Chave, E. J. The measurement of attitude. Chicago: University of Chicago Press, 1929.

Wainer, H., Fairbank, D. T., \& Hough, R. L. Predicting the impact of sample and compound life change events. Applied Psychological Measurement, 1978, 3, 311-320.

Wright, B. D. Solving measurement problems with the Rasch model. Journal of Educational Measurement, 1977, 14, 97-116.

Wright, B., \& Douglas, G. A. Best procedures for sample-free item analysis. Applied Psychological Measurement, 1977, 1, 281-295.

Wright, B. D., \& Douglas, G. A. Best procedures for items and scales with the Rasch model (Research Memorandum No. 23). Chicago: University of Chicago, Department of Education, Statistical Laboratory, 1977.

Wright, B. D., Mead, R. J., \& Draba, R. Detecting and correcting test item bias with a logistic response model (Research Memorandum No. 22) Chicago: University of Chicago, Department of Education, Statistical Laboratory, 1976.

Wright, B. D. \& Stone, M. H. Best test design. Chicago: MESA Press, 1979. 


\section{Acknowledgments}

Support for this research was provided by a grant from The Bureau of Employment and Training, Michigan Department of Labor.

\section{Author's Address}

Send requests for reprints or further information to Neal Schmitt, Department of Psychology, Snyder Hall, Michigan State University, East Lansing, MI 48824. 